\title{
O AFIXOIDE LÁ EM CONSTRUÇÕES DO PORTUGUÊS - PERSPECTIVIZAÇÃO ESPACIAL E (INTER)SUBJETIFICAÇÃO
}

\author{
Mariangela Rios de Oliveiral
}

\section{RESUMO}

Neste artigo, com base na Linguística Funcional Centrada no Uso, nos termos de Traugott e Trousdale (2013) e Bybee (2010; 2015), entre outros, investigamos o afixoide lá como subparte de três construções instanciadas no português brasileiro: a conectora textual (lá vai, lá está), a marcadora discursiva (vamos lá, olhe lá) e a intensificadora de grau (para lá de bonita, para lá de charmoso). Defendemos que o uso de lá nos três esquemas é motivado por inferências negociadas entre os interlocutores, a partir de propriedades do locativo, atinentes ao tipo de espacialização perspectivizada, no apontamento para lugar mais distante e vago em relação aos interlocutores, e às estratégias de (inter)subjetificação articuladas.

Palavras-chave: Perspectivização espacial, subjetificação, construção gramatical, afixoide lá.

\begin{abstract}
In this article, in accordance with Usage-Based Functional Linguistics, in terms of Traugott and Trousdale (2013,) and Bybee (2010, 2015), among others, we investigate the affixoid "lá" as a subpart of three constructions instantiated in Brazilian Portuguese: textual connector ("lá vai", "lá está"), discursive marker ("vamos lá", "olhe lá"), and degree intensifier ("para lá de bonita", "para lá de charmoso"). We argue that the use of "lá" in the three schemes is motivated by inferences that are negotiated between the interlocutors, based on properties of the locative, related to the type of perspectivized spatialization, when referring to a more distant and vague place in relation to the
\end{abstract}

1 Professora Titular da Universidade Federal Fluminense. E-mail: mariangelariosdeoliveira@gmail.com 
interlocutors, and to the strategies of (inter) subjectification.

Key-words: Space perspectivization, subjectification, grammatical construction, affixoid lá.

\section{Introdução}

Com base na Linguística funcional centrada no uso (doravante LFCU), nos termos de Traugott e Trousdale (2013) e Bybee $(2010 ; 2015)$, entre outros, investigamos neste artigo determinados padrões construcionais do português em que uma de suas subpartes é a partícula locativa lá. Interessanos pesquisar como tal partícula concorre, em termos semânticos, na configuração dos pareamentos investigados. Partimos da hipótese de que propriedades de sentido, atinentes à perspectivização espacial, e de forma, relativas à configuração monossilábica desse item, motivam sua seleção como subparte das construções pesquisadas.

Os padrões construcionais selecionados para análise são três:

(a) a construção conectora textual formada por locativo e verbo $[\mathrm{LocV}]_{\mathrm{ct}}$, nos termos de Rocha (2016):

(1) Realmente, para mim foi uma certa novidade. Então, à sua volta, jovens como a Ana estão a ler mais? A. M. Sim, e eu considero que o tempo, de facto, acaba por ser um problema maior no que toca à leitura. Hoje em dia temos horários muito pesados, depois com trabalhos extra-escolares também grandes. Horários muito grandes e depois ainda os trabalhos de casa, o estudo pessoal que tem que ser feito e depois, lá está, se queremos continuar a cultivar aquela ideia que há que gozar a juventude, que a vida tem que ser vivida e que são os nossos melhores anos, este género de filosofia depois encaixada na realidade é complicada. (Século $\mathrm{XX}$, Portugal, oral)

(b) a construção marcadora discursiva integrada por verbo e locativo [VLoc $]_{\mathrm{md}}$, conforme Teixeira (2015) e Sambrana (2017):

(2) Sua mão preta, de unhas brancas, desafivelava, fazia o troco, afivelava - independente do seu olhar, que vagava ao longe, e apenas baixava uma ou outra vez, para conferir. Maria 
Maruca quis provar aquela comida de pretos. Olhe lá... Tome cuidado... - dizia Dentinho de Arroz. Essa gente sabe muita coisa... Podem botar dentro alguma porcaria. Maria Maruca desdenhava: 'Eu lá tenho medo de feitiços'- Sua cara vermelha brilhava ao sol. Amontoaramlhe no prato o pirão de milho, e viraram-lhe, ao lado, umas colheradas do ensopado de bofe e coração. (CP, séc. XX, Br, Fic, C.Meireles, Olhinhos de gato, 1939)

(c) a construção intensificadora de grau [para lá de $\left.X_{\text {adj }}\right]_{\mathrm{ig}}$, nos termos de Venâncio (2015):

(3) Michel Teló e Thaís Fersoza escolheram um destino para lá de romântico para comemorar suas bodas de sorvete - que marcam os primeiros dois meses de casados -, Fernando de Noronha. Tanto a atriz como o sertanejo publicaram em seus perfis no Instagram nesta terça-feira, 16, fotos da viagem ao destino, um dos favoritos dos famosos brasileiros. (Disponível em: <http:/caras.uol. com.br/ verao/michel-telo-e-thais-fersoza-comemorambodas-de-sorvete-em-fernando-de-noronha\#.VM5EFGjFA U>. Acesso em 15 dez. 2014.)

Nos três exemplos apresentados, destacamos instâncias de uso de construções gramaticais do português formadas pelo afixoide lá. De acordo com Booij (2010; 2013), definimos afixoide como uma categoria gradiente, situada no intervalo entre termos lexicais, de conteúdo mais pleno, como nomes e verbos, e termos de maior sentido procedural, de conteúdo abstrato, como afixos e desinências. Nesse sentido, a partícula lá é interpretada como subparte periférica dessas construções complexas, como constituinte mais leve, em termos de sentido e forma, que, vinculada a outros elementos nucleares, concorre para a configuração de esquemas específicos. Em pesquisa do português, Braga e Paiva (2003, p. 209) se referem ao papel afixoide como uso clítico, em seu estudo específico do locativo aí.

Interessa-nos aqui investigar como a perspectivização espacial (Batoréo, 2000) e a inferência sugerida $^{2}$ (Traugott; Dasher, 2002) motivam a seleção de lá nas instanciações construcionais destacadas em (1), (2) e (3). Conforme Goldberg (1995; 2006; 2009) e Croft e Cruse (2004), definimos construção como pareamento convencional de forma e função. Assumimos que, se, por um lado, o sentido construcional não corresponde meramente à soma do sentido das subpartes envolvidas, por outro lado, cada subparte concorre para a instanciação construcional como um todo. Assim, traços semânticos do afixoide lá, como os atinentes ao nível de proximidade dos interlocutores e à sua

2 Nossa tradução livre para o termo invited inference, cunhado par Traugott e Dasher (2002), na referência à negociação de sentidos intersubjetivos em contextos específicos. 
granulidade $^{3}$ vasta, na articulação do sentido vago e impreciso que veicula, entre outros, devem impactar e motivar sua instanciação nas construções referidas.

Para dar conta de nosso objetivo e da hipótese de trabalho, este artigo se distribui em quatro seções. Na primeira, trazemos as bases teóricas da LFCU, com destaque para a abordagem construcional da gramática. Na segunda parte, voltamo-nos para o afixoide lá, enfatizando as propriedades de sentido que motivam seu recrutamento para compor as construções em estudo. Na terceira, dedicamo-nos à descrição e à análise das três construções selecionadas, a partir de dados de recentes pesquisas do português em uso; o foco reside nas propriedades do afixoide lá e sua contribuição para os padrões construcionais analisados. Por fim, na quarta seção, como considerações finais, apresentamos uma síntese dos traços caracterizadores de lá que motivam sua seleção como subparte afixoide das construções pesquisadas, com destaque para a perspectivização espacial e a (inter)subjetificação que esse constituinte articula.

\section{Linguística Funcional Centrada no Uso (LFCU)}

O campo teórico em que nos apoiamos, resultante do mais recente diálogo e parceria entre o funcionalismo de vertente norte-americana, na linha de Givón, Traugott, Bybee, Hopper, Thompson e outros, e o cognitivismo, com base nos trabalhos de Croft, Goldberg, Fillmore, entre outros, é hoje por nós nomeado de Linguística funcional centrada no uso (Bybee, 2010; 2015; Traugott, 2012; Traugott, Trousdale, 2013). Sob esse rótulo, o funcionalismo que praticamos atualmente lança seu foco de interesse em padrões de uso, em expressões que são produzidas e recebidas como um todo de sentido e forma, e que passam a cumprir funções mais gramaticais ou discursivo-pragmáticas na língua. Tais padrões emergem da combinação de três eixos motivadores: a dimensão cognitivo-experiencial, a dimensão sócio-histórica e a dimensão estrutural da própria língua. Da associação dessas três instâncias, em menor ou maior grau, são forjados, fixados e regularizados os usos linguísticos. Assim posto, parte a LFCU, com base em Traugott e Trousdale (2013), de concepção holística de gramática, dado que esta é assumida como um sistema de conhecimento linguístico hipotético, incluindo não só morfossintaxe, semântica e fonologia, mas também pragmática e funções discursivas.

Na LFCU, os padrões de uso são considerados instanciações de construções, definidas estas como modelos esquemáticos em que forma e sentido se encontram vinculadas em maior ou menor

3 De acordo com Batoréo (2000: 439), a granulidade, termo oriundo da Inteligência Artificial, define as diferenças nas regiões-de-vizinhança dos conjuntos, a partir de dois subsistemas: a) granulidade vasta do binômio cá/lá e granulidade fina ou estreita, correspondente a um ponto específico, como aqui/ai/ali. 
grau; e a língua, portanto, é entendida como o sistema simbólico de pares de estrutura e significado, como demonstrado com base em exemplificação do português em Rosário e Oliveira (2016). Assim, por exemplo, em relação a lá está, olhe lá e para lá de romântico, concernentes aos fragmentos (1), (2) e (3), apresentados na parte introdutória do presente artigo, consideramos tratar-se, respectivamente, de instâncias de uso pertencentes à classe dos conectores textuais, dos marcadores discursivos e dos intensificadores de grau. Tais usos, tomados como manifestações de esquemas altamente vinculados em termos de sentido e forma, são produzidos e compreendidos como um todo; nessas expressões, cada subparte concorre para o sentido e o formato geral. Há em comum, nos três fragmentos, o preenchimento de uma das subpartes pelo afixoide lá, que, assim, contribui, com seus traços semânticos, para a configuração de tais esquemas. Nosso problema é justamente responder a essa questão: por que lá é recrutado para compor esses esquemas? Que propriedades tem esse afixoide que o fazem preencher determinados slots $^{4}$ ?

Em consonância com a estreita relação entre sentido e forma assumida pela perspectiva construcional, fundamentamo-nos na proposta de Croft e Cruse (2004, p. 258) e Croft (2001, p. 18), a partir de seu modelo da estrutura simbólica da construção:

\section{O N S T R U Ç Ã O}

Propriedades sintáticas
Propriedades morfológicas $\quad$ FORMA
Propriedades fonológicas

\section{$\downarrow$ \\ ELO DE CORRESPONDÊNCIA SIMBÓLICA}

$\uparrow$
Propriedades semânticas
Propriedades pragmáticas

SENTIDO

Propriedades discursivo-funcionais

4 Slots são lugares esquemáticos de uma construção, passíveis de serem preenchidos e instanciados por distintos constituintes, como V, Loc e X; quanto mais esquemática é uma construção, menor sua composicionalidade e maior é a tendência à formação de types específicos do mesmo padrão, revelando sua produtividade. 
Como podemos observar, a proposta dos autores procura dar conta de todos os níveis de uso de uma dada construção, tanto em termos de suas propriedades formais quanto referenciais. A conexão entre convencionalização de sentido e forma é interna à construção, envolvendo aspectos mais arbitrários e outros mais motivados. Trata-se, portanto, de um modelo holístico de análise, que procura dar conta das distintas dimensões aí envolvidas e suas interfaces.

\section{Espacialização e (Inter)subjetificação ${ }^{5}$}

Em abordagem cognitivista, Batoréo (2000, p. 26) destaca que o espaço é considerado um dos domínios mais transparentes e complexos da interdependência da Linguagem e Cognição e que esquemas espaciais são recrutados para esquemas formados por outras expressões de caráter nãoespacial. Na mesma vertente teórica, Ferrari (2011, p. 93) declara que recorremos ao conhecimento de base experiencial relativo ao espaço e o projetamos para o domínio abstrato de tempo. Assim posto, tal concepção retoma a clássica derivação de base localista espaço $>$ tempo $>$ texto, proposta por Traugott e Heine (1991). Essa trajetória tem a ver com: a) a espécie de perspectivização espacial articulada na interação; b) o tipo de percepção que o indivíduo tem do que o rodeia; c) a representação que o esse indivíduo tem do meio ambiente em relação a seu interlocutor. Tais questões se encontram detalhadas em Batoréo (2000) e tratadas empiricamente em Oliveira e Batoréo (2014), a partir de estudo contrativo de construções formadas por locativos no PB e o no PE.

A espacialização pode ainda ser considerada com base na semântica de frames, tal como formulada por Fillmore (1988). O termo corresponde a um tipo de enquadramento, de sistema estruturado de conhecimento, fundado na experiência cotidiana, que é acionado nas interações. De acordo com tal perspectiva, esse enquadramento atribui sentido às nossas declarações, que se encontram, assim, dependentes do tipo de frame acionado. Portanto, há motivação entre determinados contextos de uso, nos termos de Diewald (2002; 2006), seu nível de menor ou maior abstração, estratégias de (inter)subjetificação e o afixoide lá instanciado nas construções pesquisadas. A semântica de frames também guarda correspondência com o tipo de sequência tipológica articulada (MARCUSCHI, 2002; 2008), uma vez que porções textuais descritivas e narrativas tendem a se organizar a partir de molduras mais objetivas, enquanto sequências injuntivas, dialógicas ou expositivo-dissertativas enquadram cenas mais abstratas e marcadas por (inter)subjetificação, tal como ocorre nos exemplos (1), (2) e (3). Nesses exemplos, prepondera a marca (inter)subjetiva, que se observa tanto no tom

5 Embora Traugott e Dasher (2002) se refiram ao termo subjetificação, optamos aqui por complementá-lo com a anteposição de (inter), levando em conta que o foco desse processo é a díade falante/escritor \& ouvinte/leitor; nesse sentido, a expressão do locutor e suas estratégias persuasivas acabam por atingir o interlocutor de modo inevitável. 
dialógico, mais explícito em (1) e (2), como na manifestação opinativa, destacada em (3).

Para a abordagem da (inter)subjetificação, fundamentamo-nos em Traugott e Dasher (2002), com base na proposição da inferência sugerida, entendida como uma espécie de acordo tácito, no plano interacional, em que os interlocutores negociam sentidos e crenças, em nível de maior abstração, para além do plano meramente informacional. Uma das manifestações da inferência sugerida é justamente a (inter)subjetificação, pela qual os locutores, além de manifestarem sua avaliação do que verbalizam e veiculam, atuam ainda sobre os interlocutores, no intuito de agirem sobre estes, tentando seduzi-los no jogo interacional. Para tanto, mudanças semânticas ocorrem, uma vez os novos sentidos negociados são forjados com base em termos já existentes, que têm seu conteúdo abstratizado para dar conta dos novos propósitos comunicativos. De acordo com Traugott e Dasher (2002), a (inter) subjetificação é um dos mais fortes e representativos mecanismos da mudança semântica no uso linguístico, constituindo etapa inicial de muitos processos de mudança gramatical.

Assumimos que a (inter)subjetificação veiculada por intermédio do afixoide lá, motivada pelos jogos inferenciais e arranjos verbais de que participa, é um fator relevante para seu recrutamento na formação das construções aqui analisadas. De acordo com Bueno (1968) e Cunha (1987), o locativo lá provém do termo latino illac, na referência àquele lugar, como espaço mais distante dos interlocutores. Segundo Batoréo (2000), além da distância aludida, lá também porta propriedades de granulidade vasta, uma vez que se refere a espaço inespecífico e indeterminado, traço que o distingue, por exemplo, do locativo ali. Consideramos que tanto o distanciamento do espaço interlocutivo quanto a granulidade vasta constituem traços motivadores para o uso de lá tanto nos padrões construcionais aqui estudados quanto em outros do português. Martelotta e Rêgo (1996, p. 237), por exemplo, em estudo pioneiro, fundamentados em abordagem funcionalista clássica, já se referem aos contextos em que a partícula lá mostra sinais de gramaticalização e destacam funções que são assumidas por ela no ato discursivo, como em usos do tipo sei lá, uma doença lá, de lá para cá, entre outros.

Na descrição gramatical do português, o locativo lá se situa na classe dos advérbios, considerada de extrema mobilidade semântica e funcional (BECHARA, 1999, p. 288). Camara Jr (1979, p. 123), ao identificar usos conectivos de determinados advérbios, alerta para certas diretrizes que devem ser pesquisadas, descritas e classificadas no tratamento dessa categoria, a fim de que se retire de sua abordagem a marca da arbitrariedade com que, em geral, é descrita. Mesmo nos estudos mais recentes sobre a língua portuguesa do Brasil, tais como os de Ilari et al (1990), Neves (2000; 2002), Castilho, (2010) e Bagno (2011), a categoria adverbial é caracterizada como uma classe pouco nítida, de 
contornos difusos, integrada por membros muito distintos, incapazes de compartilhar maior conjunto de traços.

No caso do locativo lá, a imprecisão categorial manifesta-se de modo ainda mais acentuado. Trata-se prototipicamente de um advérbio não-predicativo (Ilari et al, 1990) e não-modificador (Neves, 2000). Como marcas adicionais da subclasse dos locativos, que confirmam sua marginalidade característica em relação aos demais advérbios, citam-se a natureza pronominal e a foricidade de que se reveste. Lá constitui uma proforma que, na perspectiva construcional assumida pela LFCU, atua como afixoide, como subparte mais periférica de esquemas complexos, como as construções abordadas a seguir.

\section{O afixoide $L A ́$ em construções do português}

Nesta seção, selecionamos três padrões construcionais para descrição e análise. Privilegiamos as instâncias de uso em que o slot do locativo (Loc) é preenchido por lá. Interessa-nos não só a configuração de cada um desses padrões como também o que há de comum nos mesmos, a partir do recurso ao mesmo afixoide.

\section{1. $[\mathrm{LocV}]_{\mathrm{ct}}$}

$\mathrm{A}[\mathrm{LocV}]_{\mathrm{ct}}$ é uma construção esquemática, ou seja, tem alto nível de abstração, com suas subpartes podendo ser preenchidas por constituintes distintos, formando-se assim microconstruções ou types específicos, nos termos de Traugott e Trousdale (2013). O tipo de conexão realizado por esse pareamento é retroativo-propulsor, conforme Tavares (2012), ou seja, vincula o que foi declarado, anaforicamente, ao que será declarado, cataforicamente.

De acordo com Rocha (2016) e Oliveira e Rocha (2016), nessa construção, uma das possibilidades de preenchimento das subpartes Loc e V é justamente aquela formada pelo afixoide lá seguido dos constituintes verbais está ou vai, nas formações lá está e lá vai. Assim, embora a $[\mathrm{LocV}]_{\mathrm{ct}}$ desempenhe, em termos gerais, função conectora, a depender das subpartes envolvidas, efeitos de sentido específicos são obtidos. Desse modo, lá está e lá vai, como microconstruções do esquema maior $[\mathrm{LocV}]_{\mathrm{ct}}$, são instanciadas como em:

(4) Nós à bocado falámos da liberdade se falou-se da censura, portanto, da liberdade de 
imprensa. Quando vêtelevisão, acha que a verdade está a passar, a verdade dos acontecimentos, ou, se há manipulação, que as pessoas podem gerir o que ouvem e serem capazes de ser objectivas perante as imagens que recebem? A. M. O problema dos meios de comunicação é muito complexo. Lá está: saber gerir a liberdade. Eu, desde muito pequena que acompanho o meu pai, que é da área da comunicação social, em conferências e, esse é um tema que eu já ouvi debater muito por gente que melhor do que eu saberá falar nele. (Século XX, Portugal, oral)

(5) Deve fazer umas quadrinhas novas... Porque não faz? - Fiz já. - Pode recitar? - Pois não. - Diga lá. - Lá vai: Ai, Filomena, Se eu fosse como tu, Punha uma máscara Na cara do Dudu. (Século XX, Brasil, ficção)

Tanto em (4) quanto em (5), lá está e lá vai apresentam alto nível de vinculação semânticosintática, formando um chuncking ${ }^{6}$, nos termos de Bybee $(2010 ; 2015)$. Nesses usos, tanto o locativo lá quanto o elemento verbal nuclear perdem traços de sua categoria prototípica, em prol da formação de um pareamento de função gramatical, no nível da conexão textual. Em ambos os fragmentos, representativos de textos escritos, $\mathrm{a}[\mathrm{LocV}]_{\mathrm{ct}}$ é instanciada antes de pausa menor e se encontra precedida por pausa maior. O preenchimento do slot Loc pelo afixoide lá confere também à construção certo caráter mostrativo: ao mesmo tempo em que prepara o interlocutor sobre o que será declarado após os dois pontos - a especificação do problema dos meios de comunicação, em (4), e a quadrinha recitada em (5), desloca essa amostra para um espaço distante e inespecífico, afastado do ambiente mais próximo em que se encontram os interlocutores. Sequências dissertativo-argumentativas, como (4), e dialógicas, como (5), são ambientes motivadores para instanciações desse tipo; em tais contextos, por inferência sugerida, o escritor atua sobre o leitor, convidando-o a partilhar, intersubjetivamente, sentidos mais inferíveis, de natureza pragmático-discursiva, como o traço mostrativo presente nas duas instanciações construcionais destacadas em (4) e (5).

Em pesquisa sincrônica sobre a $[\mathrm{LocV}]_{\mathrm{ct}}$, com base em levantamento exaustivo de textos do

6 Para a autora, um chuncking é um processo cognitivo de domínio geral pelo qual são encadeadas, em termos de sentido e forma, as unidades linguísticas. Trata-se de um mecanismo básico para a formação de unidades mais complexas, tanto no nível gramatical, como as construções SN, SV ou SPrep, quanto no nível lexical, como os compostos guardachuva ou quebra-cabeça, por exemplo. 
século XX no Corpus do Português ${ }^{7}$, Rocha (2016, p. 92) encontra 90 dados do uso desse padrão construcional. Das seis microconstruções pesquisadas pela autora, tomadas como as mais frequentes no português, as preenchidas pelo afixoide lá são as menos recorrentes, como podemos observar pela Tabela 1:

\begin{tabular}{|c|c|c|c|c|c|c|c|}
\hline COMBINAÇÃO & Aqui está & Aí está & Lá está & Aí vem & Aí vai & Lá vai & TOTAL \\
\hline Total de ocorrências & 96 & 155 & 149 & 57 & 29 & 176 & 662 \\
\hline Ocorrências no Cont. Isolado & 9 & 52 & 6 & 11 & 7 & 5 & 90 \\
& $(9,37 \%)$ & $(33,55 \%)$ & $(4,03 \%)$ & $(19,30 \%)$ & $(24,14 \%)$ & $(2,84 \%)$ & $(13,59 \%)$ \\
\hline
\end{tabular}

Tabela 1: Frequência das microconstruções do esquema $[\mathrm{LocV}]_{\mathrm{ct}}$

Nessa tabela, a linha "Total de ocorrências" diz respeito ao levantamento geral de expressões usadas, seja em vinculação menor das subpartes, nas quais Loc e $\mathrm{V}$ atuam efetivamente como elementos mais lexicais, seja em arranjos mais integrados, quando atuam de fato como instâncias da $[\mathrm{LocV}]_{\mathrm{ct}}$. A segunda linha horizontal, sob o rótulo "Ocorrências no contexto isolado", assumindo a terminologia de Diewald (2002; 2006), refere-se somente aos casos em que se detectam usos conectores textuais das expressões levantadas. Comparando-se os resultados numéricos de ambas as linhas, podemos constatar que os contextos "isolados", nos quais temos a efetiva instanciação da $[\mathrm{LocV}]_{\mathrm{ct}}$, são pouco produtivos no corpus pesquisado, registrando reduzida frequência de uso.

Consideramos, na Tabela 1, que a menor frequência no uso de lá como preenchedor da primeira subparte da [LocV]ct deve-se justamente à granulidade vasta e ao maior distanciamento articulados por esse locativo. Dos dados de Rocha (2016), constatamos que a maior frequência de preenchimento do slot Loc é a de aí, termo que aponta justamente para o espaço do interlocutor, de modo mais preciso e específico, num tipo de articulação de sentido que parece favorecer a proximidade na negociação de

7 Acessado através do link: www.corpusdoportugues.org

8 De acordo com Diewald (2002; 2006), o contexto isolado refere-se ao estágio em que uma mudança linguística se efetiva e consolida; trata-se da fase em que um novo membro é convencionalizado e incorporado ao paradigma da língua, distinguindo-se por completo dos arranjos iniciais que o motivaram. 
sentidos entre os atores da interação. Das 90 ocorrências levantadas, a grande maioria, perfazendo 70 dados, são exemplares instanciados por aí, tendo a microconstrução aí está a maior frequência.

\section{2. $[\text { VLoc }]_{\mathrm{md}}$}

Conforme se encontra em Oliveira e Teixeira (2015; 2017), Teixeira (2010; 2015) e Sambrana (2017), a [VLoc $]_{\mathrm{md}}$ constitui, no português contemporâneo, um esquema altamente vinculado e muito produtivo, notadamente em interações mais informais e injuntivas, nas quais preponderam pressões intersubjetivas, nos termos de Traugott e Dasher (2002). A íntima vinculação de suas subpartes, com perda acentuada das propriedades típicas de seus constituintes (verbo e pronome locativo), contrasta com o modo mais desvinculado com que $[\mathrm{VLoc}]_{\mathrm{md}}$ atua nos textos em que ocorre. A função precípua dessa construção é pontuar a sequência em que se insere, orientando o foco do interlocutor para o que se intenta destacar; trata-se de um tipo de inferência sugerida específico.

Entre a distinta conceituação dos marcadores discursivos na literatura linguística, partimos da seguinte, que consideramos contemplar a funcionalidade da $[\text { VLoc }]_{\mathrm{md}}$ :

\footnotetext{
Trata-se de amplo grupo de elementos de constituição bastante diversificada, envolvendo, no plano verbal, sons não lexicalizados, palavras, locuções, e sintagmas mais desenvolvidos, aos quais se pode atribuir homogeneamente a condição de uma categoria pragmática bem consolidada no funcionamento da linguagem. Por seu intermédio, a instância da enunciação marca presença forte no enunciado, ao mesmo tempo em que se manifestam importantes aspectos que definem sua relação com a construção textual-interativa. (RISSO; SILVA; URBANO; 2002, p. 21)
}

Assim posto, assumimos que a [VLoc $]_{\mathrm{md}}$ se encontra em ponto avançado na rota de mudança gramatical, dado que a marcação discursiva atua no nível pragmático da língua, para além da dimensão sintática. Em termos construcionais, a menor integridade de conteúdo e forma das subpartes $\mathrm{V}$ e Loc revela a menor composicionalidade, ou seja, a menor autonomia de cada subparte, e a maior esquematicidade, nos termos de Traugott e Trousdale (2013), desse pareamento.

A subparte Loc, em papel afixoide, contribui para o sentido construcional, perspectivando V, na formação de um elemento da classe dos marcadores discursivos do português. A depender do preenchimento de Loc, altera-se a referida perspectiva, como demonstrado em Sambrana (2017), com base no fragmento (2), ilustrado na seção introdutória. Nesse fragmento, o marcador olhe lá abre espaço para o conselho dado a Maria Maruca: Tome cuidado... Essa gente sabe muita coisa... Podem botar dentro alguma porcaria. A instanciação de lá nessa formação concorre para articulação 
do sentido de aconselhamento e recomendação de toda a sequência, como se num lugar vago e mais distante (lá) estivesse o perigo (Podem botar dentro alguma porcaria). O sentido de aconselhamento se articula não só pelo preenchimento do slot $\mathrm{V}$ por olhe, usado metaforicamente com sentido cognitivo, como também pela instanciação de lá no slot Loc, como se o perigo e demais riscos estivessem de fato num espaço mais distante e pouco nítido.

Um novo efeito de sentido se instaura quando, conforme demonstrado em Teixeira (2015, p. 198), o afixoide lá é combinado com verbo de deslocamento espacial, formando outra microconstrução, como a seguir:

(6) Houve, mas só de passagem. O que houve mesmo, de fato, foi a aprovação do primeiro turno da emenda da reeleição na Câmara. Dirão que depende do ponto de vista. Vá lá. Mas o que não é pura interpretação é a vontade com que o senador Antônio Carlos assumiu seu posto no Senado. Mostrou as primeiras garras, que agradou muito à esquerda sem desagradar ao poder... (Século XX, Brasil, notícia)

Em instanciações como (6), destaca-se o sentido concessivo articulado por vá lá. Esse uso, por inferência sugerida, concorre para incrementar o tom opinativo, fazendo com que o emissor desloque para espaço mais difuso e distante alguma interpretação inicial (Dirão que depende do ponto de vista); em seguida, após vá lá, esse mesmo emissor traz à cena o que de fato intenta destacar (Mas o que não é pura interpretação é a vontade com que o senador Antônio Carlos assumiu seu posto no Senado). Assumimos que essa propriedade de deslocamento e de vagacidade, de distanciamento para um ponto difuso, motiva a seleção do afixoide lá em tais formações. A marca do descomprometimento de vá lá coaduna-se com a impessoalidade da forma verbal vá, com o traço dissertativo-argumentativo do fragmento (6) e com o frame abstrato de todo o contexto.

Quando a subparte V é preenchida pela forma verbal na primeira pessoa do plural, altera-se o efeito do sentido construcional:

(7) O senhor poderia dar um balanço de quantos ou quanto economizou com isso? Vamos lá: de informática, eu cancelei 450 milhões com várias empresas, inclusive a da prefeitura, que não é da prefeitura, uma empresa privada que substituiu o CPD, o Centro de Processamento de Dados da prefeitura. (Século XX, Brasil, entrevista)

Por intermédio de vamos lá, tal como ilustrado em (7), articula-se um tipo específico de sentido 
injuntivo com o qual o emissor convida o interlocutor a partilhar a informação a seguir, preparando-o para o que vai se declarado, destacando o tom intersubjetivo do fragmento. Ao usar a primeira pessoa do plural, instaura-se a adesão e o comprometimento, no convite a que o ouvinte ou leitor endosse o que será referido. O afixoide lá nessa formação concorre para instaurar a marca da abstração de todo o trecho. Como demonstra Teixeira (2015, p. 230), o traço de exortação derivado do sentido de se delocar para além de onde se encontram os interlocutores permanece nos usos de vamos lá, indicando, como marcador, uma exortação/estímulo/incentivo para atuar em outra instância, deslocando o ponto de vistalatenção do interlocutor.

Tomando por fonte também o Corpus do Português, Teixeira (2015) levanta, no século XX, 20 ocorrências de vá lá e 26 de vamos lá como instanciações da [VLoc] $]_{\mathrm{md}}$. Esses usos, de fato, são registrados na língua, de acordo com o banco de dados pesquisado, desde o século XIX. A autora também detecta e investiga, como microconstruções da $[\mathrm{VLoc}]_{\mathrm{md}}$ preenchidas no slot Loc por lá, as seguintes formações: espera lá, olha lá, vê lá, diga lá, sei lá, sabe lá e quero lá. Cada um desses types, conforme a natureza semântica e gramatical de V, assume sentido mais específico, em termos de marcação discursiva; em comum, partilham o preenchimento da segunda subparte pelo afixoide lá, o que confere a todos, em maior ou menor grau, marca de imprecisão, vaguidão, distanciamento ou pouca importância, chegando até mesmo a sentido negativo, no caso do type sei lá, conforme demonstrado em Oliveira e Santos (2011).

\section{3. [para lá de $\left.\mathrm{X}_{\mathrm{adj}}\right]_{\mathrm{ig}}$}

O terceiro padrão construcional aqui abordado é aquele instanciado pelo afixoide lá, antecedido por para e seguido por de $X$, este, via de regra, de base adjetiva. Trata-se de uma construção gramatical parcialmente esquemática, uma vez que apresenta subpartes preenchidas (para, lá, de) e outra em slot (X). A construção tem função de grau intensificador, conforme se encontra em Silva (2014, p. 69), para quem intensidade é localização. De acordo com autor

entendemos a conceitualização do grau como uma atividade semântico-cognitiva e discursivo-pragmática fundada em nossas experiências individuais (físicas e/ou afetivas) e socioculturais.

Nessa conceitualização, escalonam-se, de certa maneira, noções relativas a conceitos referenciais, eventos e estados de coisas em geral que são tomados, de algum modo, como suscetíveis a um escalonamento, conforme determinados parâmetros e convenções. Tal conceitualização, associada ao propósito discursivo e ao contexto em que se dá, evidentemente, tem implicações em seu modo de expressão. (SILVA, 2014, p. 38-39) 
Com base em Venâncio (2015), ilustramos instanciações da [para lá de $\left.X_{\text {adj }}\right]_{\mathrm{ig}}$ :

(8) Nesta terça-feira (12), é o aniversário de 22 anos da modelo britânica Cara Delevingne, uma das tops mais simpáticas da atualidade. A seguir, o UOL Moda selecionou 22 imagens que provam que, além de querida e com uma vida social para lá de agitada, ela é a modelo mais interessante do momento. (Disponível em: <http://noticias.bol.uol.com. br/fotos /entretenimento/2014/08/ 11/22-vezes-em-que-cara-delevingne-provou-que-e-a-topmais-querida-do-momento.htm>. Acesso em: 10 ago. 2012)

(9) Se você é tipo a gente, que adora acompanhar todo o luxo e riqueza dos pets dos glamurettes, vai adorar essa notícia: pedimos a Deborah Falci, Tania Derani, Luciana Tranchesi e Walério Araújo, donos de cachorrinhos pra lá de fofos, para contarem como éo dia a dia dos seus bichinhos. Vem com a gente! (Disponível em: <http://glamurama.uol.com. br/au-au-a-vida-puro-charme-dos-caes-de -quatro-glamurettes-vem-espiar/>. Acesso em: 30 ago. 2014)

Como podemos observar, em (8) e (9), a instanciação de [para lá de $\left.X_{\text {adj }}\right]_{\text {ig }}$ concorre para incrementar sentido atributivo: em (8), intensifica a agitação da vida social da modelo britânica Cara Delevingne; em (9), destaca a fofura de cachorrinhos de artistas famosos brasileiros. O locativo lá, por conta de sua granulidade vasta e do distanciamento espacial que articula, é o item recrutado para a instauração do sentido intensificador. A distância no espaço, sentido fonte do locativo, se encontra, por força de pressões de ordem contextual e pragmática, redimensionada e convertida em distância no nível da atribuição referida; assim, para lá de agitada e pra lá de fofos atuam em função intensificadora, ao articularem sentido que designa algo para além do limite do qualificador inicial agitada e fofos, fazendo a referência ultrapassar a barreira da simples adjetivação.

Os fragmentos (8) e (9) ilustram ainda o contexto preferencial de instanciação da [para lá de $\left.\mathrm{X}_{\mathrm{adj}}\right]_{\mathrm{ig}}$ : declarações informais, injuntivas ou dialógicas, marcadas por forte (inter)subjetividade e tom opinativo. Em contextos assim forjados, [para lá de $\left.\mathrm{X}_{\text {adj }}\right]_{\mathrm{ig}}$ torna-se mais um elemento a concorrer, coesivamente, para a articulação de pontos de vista enfáticos. Justamente por essa característica discursivo-pragmática, a instanciação da [para lá de $\left.\mathrm{X}_{\text {adj }}\right]_{\mathrm{ig}}$ tem sido mais levantada em blogues, em sites de moda, de entretenimento, colunas sociais, entre outros, como demostra Venâncio (2015). Tal tendência permite ainda que se hipotetize ser essa construção mais recente na trajetória do PB, dado que investigações preliminares por nós empreendidas ainda não levantaram tal ocorrência no PE. 
Assumimos que [para lá de $\left.\mathrm{X}_{\mathrm{adj}}\right]_{\mathrm{ig}}$ tenha como contextos originais ou típicos, conforme a terminologia de Diewald (2002; 2006), formações mais composicionais, em que cada subparte corresponde a sua classe inicial e em que X constitui um nome substantivo de sentido espacial, como em (10), temporal, como em (11), ou quantificador, como em (12), também extraídos de Venâncio (2015):

(10) Olharam através da extensão imensa dos campos de algodão de Gerald O'Hara, recentemente arados e contemplaram o horizonte encarniçado. Agora que o Sol estava prestes a sumir-se atrás das colinas, para lá do rio Flint, o calor tépido daquela tarde de Abril começava a dar lugar a uma brisa suave e fresca. (Disponível em: $<$ http://vitallivros.xpg.uol. com.br/E\%20o\%20vento\%20levou.pdf>. Acesso em: 14 ago. 2014)

(11) Excelente gravação. O som ficou ótimo, e o contraste realmente ficou um pouco exagerado. Mais ve tava com muito sol nesse dia, o que eu gravei já eram pra lá das 19:30 hs...Eu particularmente gosto de um contraste mais forte. Abcs. (Disponível em: $<\mathrm{http}: / / \mathrm{www}$. radio.uol.com.br/\#/letras-e-musicas/maria-scombona/pra-naodesvairar/1013 764>. Acesso em: 22 dez. 2014)

(12) Como o fotojornalista já está acostumado com essa prática no dia a dia, é ele o profissional requisitado ultimamente para cobrir as festas de casamento, tirar pra lá de três mil fotos, e depois criar um álbum com imagens conceituais e artísticas que estão mais para compor livro de arte. (Disponível em: < http://portaltagit.ne10.uol.com.br/cult ura/17637/ album-de-casamento-e-quase-um-livro-de-arte/>. Acesso em: 18 set. 2014)

Tomando por base a teoria localista, como apresentada em Batoréo (2000), podemos estabelecer o cline de abstratização espaço > tempo > texto (quantificação) a partir dos três fragmentos (10), (11) e (12). Nessa trajetória, para lá do rio Flint, em (10), revela maior composicionalidade, uma vez que cada uma das subpartes (para, lá, do rio Flint) preserva seus traços categoriais de fonte (preposição, pronome locativo, Sprep locativo); trata-se de um arranjo circunstancial locativo que integra sequência marcada por forte perspectivização espacial. Em (11), temos o circunstanciador temporal pra lá das 19:30 hs, num fragmento caracterizado por maior subjetividade e marcas da primeira pessoa (eu gravei, eu particularmente gosto, abcs). Por fim, em (12), pra lá de três mil fotos complementa o verbo tirar, destacando, de outra parte, o número de fotos tiradas; nesse fragmento, temos o nível de abstração do locativo lá incrementado por conta de seu preenchimento catafórico a 
partir de três mil fotos, que já não corresponde a um marco espacial ou temporal.

Na comparação dos três fragmentos, detectamos que, em (12), tanto a preposição, quando o locativo e o de $X$ se destituem de seus traços de categoria fonte em prol de maior vinculação semântico-sintática. Nesse sentido, podemos dizer que (12) exibe menor composicionalidade face a (10) e (11). Por outro lado, embora quantificação seja sentido mais abstrato em relação a espaço e tempo, ainda não estamos diante da efetiva [para lá de $\left.\mathrm{X}_{\text {adj }}\right]_{\mathrm{ig}}$ mas sim de uma configuração textual correspondente, por hipótese, ao contexto classificado como crítico de Diewald (2002; 2006), num nível de articulação que antecede a efetiva construção de grau intensificadora, tal como ilustrada em (8) e (9).

A seguir, apresentamos o levantamento da produtividade desses padrões no PB contemporâneo, com base em Venâncio (2015, p. 59):

\begin{tabular}{|c|c|c|}
\hline Combinação & Ocorrências & Nível de vinculação \\
\hline Para lá de $\mathrm{X}_{\text {loc }}$ & 26 & baixa \\
\hline Para lá de $\mathrm{X}_{\text {temp }}$ & 4 & baixa \\
\hline Para lá de $\mathrm{X}_{\text {quant }}$ & 9 & média \\
\hline [para lá de $\left.\mathrm{X}_{\text {adj }}\right]_{\mathrm{ig}}$ & 339 & alta \\
\hline Total & 378 & \\
\hline
\end{tabular}

Tabela 2: Frequência e níveis de vinculação de "para lá de $X$ "

De acordo com a Tabela 2, constatamos a majoritária frequência da [para lá de $\left.X_{\text {adj }}\right]_{\text {ig }}$ em relação aos demais arranjos, esses menos vinculados, em que $\mathrm{X}$ é preenchido por elemento de natureza circunstancial locativa, como em (10), circunstancial temporal, como em (11), e por elemento quantificador, como em (12). Assumimos que esses usos antecedem e motivam, num cline de crescente integração semântico-sintática, a efetiva [para lá de $\left.X_{\text {adj }}\right]_{i g}$, considerada, neste estágio, contexto isolado, nos termos de Diewald (2002; 2006). Embora a pesquisa de Venâncio (2015) seja de viés sincrônico, assumimos que os quatro tipos de expressões apresentadas na Tabela 2 correspondem, na trajetória da língua, a contextos inicias de mudança linguística, tal como (10) e (11), passando a fases de polissemia e ambiguidade, como ocorre em (12), e chegando a usos como os ilustrados em (8) e (9), quando se instancia a [para lá de $\left.X_{\text {adj }}\right]_{i g}$. Nesse sentido, em termos do PB contemporâneo, defendemos que os quatro estágios de vinculação convivem e competem pelo uso, na representação atual de distintas fases da língua. Em tais estágios, o afixoide lá, por conta de sua granulidade vasta e maior distanciamento do espaço interlocutivo, atua como subparte dependente, como elemento que 
marca afastamento no espaço, no tempo, na quantidade e na atribuição, respectivamente. O sentido de grau intensificador articulado na [para lá de $\left.\mathrm{X}_{\mathrm{adj}}\right]_{\mathrm{ig}}$ é motivado por intermédio da estreita relação entre maior distanciamento e consequente aumento de intensidade atributiva.

\section{Considerações Finais}

A descrição e a análise das instâncias de uso dos três padrões construcionais aqui selecionados, com foco no papel afixoide de lá em cada padrão, permitem que cheguemos a algumas constatações e generalizações, listadas a seguir:

a. Traços semânticos de lá, atinentes ao nível de distanciamento maior em relação aos interlocutores e aos objetos da interação, bem como a granulidade vasta, motivam sua instanciação como afixoide em construções complexas do português.

b. O afixoide lá, ainda que instanciado em padrões distintos, como nas três construções aqui abordadas, preserva os referidos traços, que são redimensionados e combinados com as demais subpartes das construções, concorrendo para o novo pareamento de sentido e forma.

c. Nas sequências em que são instanciadas essas construções, prepondera o frame não espacial, ou seja, o espaço é perspectivizado como domínio abstrato; fragmentos injuntivos, dialógicos e dissertativo-argumentativos configuram-se como os ambientes textuais ótimos para os usos aqui pesquisados.

d. Em termos de inferência sugerida, a (inter)subjetividade prepondera; o locutor age sobre o interlocutor, negociando o espaço vago e impreciso de lá na formação de esquemas portadores de funções gramaticais, como conexão textual, marcação discursiva e intensificação de grau.

e. Na construção $[\mathrm{LocV}]_{\mathrm{ct}}$, o preenchimento da primeira subparte pelo afixoide lá ratifica o sentido mostrativo do conector instanciado, ao mesmo tempo em que desloca o objeto a ser mostrado, no caso, declarações, opiniões ou pontos de vista, para espaço difuso e abstrato, afastado do contexto em que se situam os interlocutores.

f. Na construção [VLoc $]_{\mathrm{md}}$, o afixoide lá, ocupando o slot da segunda subparte, de acordo com suas propriedades semânticas, pode concorrer na articulação de sentido concessivo (vá lá), persuasivo (vamos lá) e mesmo negativo (sei lá), entre outros efeitos, a depender do preenchimento de V.

g. Na construção [para lá de $\left.\mathrm{X}_{\mathrm{adj}}\right]_{\mathrm{ig}}$, o afixoide lá concorre para incrementar o nível de distanciamento do atributo X, concorrendo, assim, para o sentido intensificador de grau; a adjetivação, por conseguinte, assume maior dimensão, em efeito obtido por intermédio do distanciamento e da granulidade vasta de lá. 
Em termos gerais, com os resultados aqui sumarizados, destacamos a importância da dimensão espacial, da teoria localista, como origem e base para a mudança semântica e gramatical da língua. De outra parte, ratificamos o papel de cada subparte, com suas propriedades específicas, para o sentido e o formato construcional, na fixação do chamado elo de correspondência simbólica, nos termos de Croft (2001).

\section{REFERÊNCIAS}

BAGNO, M. (2011). Gramática pedagógica do português brasileiro. São Paulo: Parábola.

BATORÉO, H. (2000). Expressão do espaço no português europeu: contributo psicolinguístico para o estudo da linguagem e cognição. Lisboa: Fundação Calouste Gulbenkian.

BECHARA, E. (1999). Moderna gramática portuguesa. 37ª Ed. Rio de Janeiro: Lucerna BOOIJ, G. (2013). Morphology in Construction Grammar. In Hoffmann and Trousdale (eds.), p. 255-273. . (2010). Construction Morphology. Oxford: Oxford University Press.

BRAGA, M. L; PAIVA, M. C. (2003). Do advérbio ao clítico é isso aí. IN: RONCARATI, C; ABRAÇADO, J. (org). Português brasileiro - contato linguístico, heterogeneidade e história. Rio de Janeiro: 7Letras, p. 206-212.

BUENO, F. S. (1968). Grande dicionário etimológico-prosódico da língua portuguesa. São Paulo: Saraiva.

BYBEE, J. (2015). Language Change. Cambridge: Cambridge University Press. . (2010). Language, Usage and Cognition. New York: Cambridge University Press.

CAMARA, Jr, J. M. (1979). História e Estrutura da Língua Portuguesa. Rio de Janeiro: Padrão. CASTILHO, A. T. (2010). Nova gramática do português brasileiro. São Paulo: Contexto.

CROFT, W; CRUSE, D. A. (2004). Cognitive Linguistics. Cambridge: Cambridge University Press.

CROFT, W. (2001). Radical Construction grammar: syntactic theory in typological perspective. Oxford: Oxford University Press. 
CUNHA, A. G. (1987). Dicionário etimológico Nova Fronteira da língua portuguesa. Rio de Janeiro: Nova Fronteira.

DIEWALD, G. (2006) Context types in grammaticalization as constructions. Constructions, Düsseldorf. Disponível em: <www.constructions-online.de:0009- 4-6860>.

. (2002). A model of relevant types of contexts in grammaticalization. In: WISCHER, I;

DIEWALD, G (eds). New reflections on grammaticalization. Amsterdam/Philadelphia: John Benjamins, p. 103-120.

FERRARI, L. (2011). Introdução à Linguística Cognitiva. São Paulo: Contexto.

FILLMORE, C. J. (1988). On grammatical constructions. Califórnia: UCB.

GOLDBERG, A. (2009). The nature of generalization in language. Cognitive Linguistics

20-1, p. 93-127

. (2006). Constructions at work: the nature of generalization in language. Oxford: Oxford University Press.

(1995). Constructions: a construction approache to argument structure. Chicago: The University of Chicago Press.

ILARI, R. et al. (1990). Considerações sobre as posições dos advérbios. In: Ataliba T, de C. (org.) Gramática do Português Falado: Vol. I: A ordem, p. 63-142.

MARCUSCHI, L. A. (2008). Produção textual, análise de gêneros e compreensão. São Paulo: Parábola.

. (2002). Gêneros textuais: definição e funcionalidade. IN: DIONÍSIO, A; MACHADO, A; BEZERRA, M. A (org) Gêneros textuais \& ensino. Rio de Janeiro: Lucerna, p. 19-36.

MARTELOTTA, M. E; RÊGO, L. (1996). Gramaticalização de "lá”. In: MARTELOTTA, M. E; VOTRE, S. J; CEZARIO, M. M. (org). Gramaticalização no português do Brasil: uma abordagem funcional. Rio de Janeiro: Tempo Brasileiro/UFRJ, p. 237-250.

NEVES, M. H. M. (2002). Os advérbios circunstanciais (de lugar e tempo). In: Ilari, R. (org.) Gramática do Português Falado, Vol. II: Níveis de Análise Linguística. $4^{\mathrm{a}}$ ed. rev. Campinas, SP: 
Editora da UNICAMP.

. (2000). Gramática de Usos do Português. São Paulo: Editora UNESP.

OLIVEIRA, M. R; BATOREO, H. (2014). Construções com pronomes locativos (Loc) do tipo LocV e VLoc no PB e no PE: correspondências e distinções. Revista Linguística (ALFAL) v. 30, p. 169-206.

OLIVEIRA, M. R.; ROCHA, R.A. (2016). Hierarquia contextual e construcional: correspondências e implicações. Revista Linguística, v. Esp, p. 68-82.

OLIVEIRA, M.R; SANTOS, L. (2011). Padrões de uso da expressão 'sei lá' no português. Signótica (UFG), v. 23, p. 363-384.

OLIVEIRA, M. R; TEIXEIRA, A. C. (2017). Padrões construcionais de base locativa na perspectiva do texto e da gramática do português. In: LUQUETTI, E. C. F; MOURA, S. A. (org). Linguística em perspectiva: cognição e ensino de língua e literatura. Campos dos Goytacazes: Brasil Multicultural, p. 74-91.

. (2015). Construções locativas de base verbal. In: Maria Angélica Furtado da Cunha. (org.). A gramática da oração - diferentes olhares. 1ed.Natal: EDUFRN, p. 167-192.

RISSO, M. S; SILVA, G. M; URBANO, H. (2002). Marcadores discursivos: traços definidores.

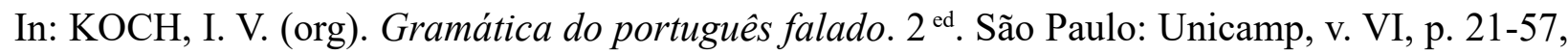
2002.

ROCHA, R. A. (2016). O esquema LocV $V_{\text {conect }}$ :mudanças construcionais e construcionalização. Tese (Doutorado em Estudos de Linguagem. Área de Concentração: Língua Portuguesa) - Instituto de Letras, UFF, Niterói.

ROSARIO, I. C. ; OLIVEIRA, M. R. (2016). Funcionalismo e abordagem construcional da gramática. Alfa: Revista de Linguística (UNESP. Online), v. 60, p. 233-259.

SAMBRANA, V. R. M. (2017). Marcadores discursivos formados pelos verbos "olhar" e "ver" - uma abordagem construcional. Dissertação (Mestrado em Estudos de Linguagem. Área de Concentração: Língua Portuguesa) - Instituto de Letras, UFF, Niterói.

SILVA, J. R. (2014). O grau em perspectiva: uma abordagem centrada no uso. São Paulo: Cortez. 
TAVARES, M. A (2012). Gramática emergente e o recorte de uma construção gramatical, em E.R. SOUZA (org), Funcionalismo linguístico: análise e descrição, São Paulo, Contexto: 33-54.

TEIXEIRA, A. C. (2015). A construção verbal marcadora discursiva VLoc ${ }_{m d}$ uma análise funcional centrada no uso. Tese (Doutorado em Estudos de Linguagem. Área de Concentração: Língua Portuguesa) - Instituto de Letras, UFF, Niterói.

. (2010). Padrões de uso de "vá lá" e "vamos lá" na norma brasileira do português: microconstruções e gramaticalização. Dissertação (Mestrado em Letras. Área de Concentração: Língua Portuguesa) - Instituto de Letras, UFF, Niterói.

TRAUGOTT, E. (2012). Toward a coherent account of Grammatical Construcionalization. Draft for a volume on historical construction grammar edited by Elena Smirnova, JóhannaBarðdal, Spike Gildea, and LotteSommerer. March $2^{\text {nd }}$.

TRAUGOTT, E; DASHER, R. (2002). Regularity in semantic change. Cambridge: Cambridge University Press.

TRAUGOTT. E; HEINE, B. (1991). Approaches to grammaticalization. Vol. 1. Focus on theoretical and methodological issues. Amsterdam: Benjamins.

TRAUGOTT, E; TROUSDALE, G. (2013). Constructionalization and constructional changes. Oxford: Oxford University Press.

VENÂNCIO, E. N. (2015). Instanciações da microconstrução intensificadora "para lá de X”" no português contemporâneo. Dissertação (Mestrado em Estudos de Linguagem. Área de Concentração: Língua Portuguesa) - Instituto de Letras, UFF, Niterói. 